\title{
Farmacologia ocular aplicada no tratamento de doenças do vítreo, retina e coróide
}

\author{
Ocular pharmacology in the treatment of vitreous, retina and choroid diseases
}

\author{
Paulo Augusto de Arruda Mello Filho ${ }^{1}$ \\ Maurício Maia ${ }^{2}$ \\ Eduardo Buchelle Rodrigues ${ }^{3}$ \\ Michel Eid Farah ${ }^{4}$
}

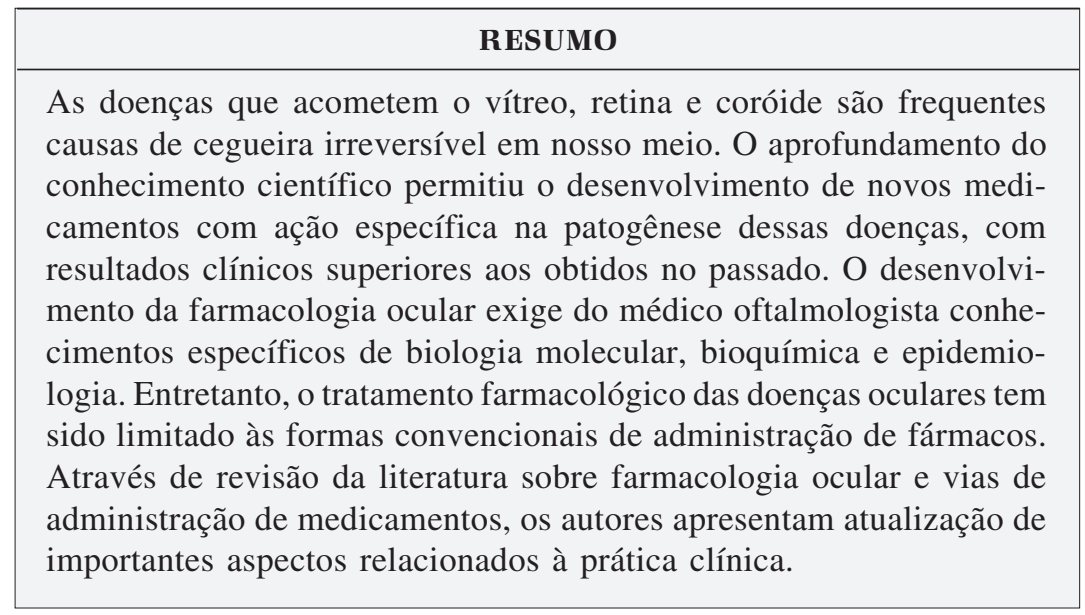

Descritores: Doenças oculares/quimioterapia; Doenças retinianas/quimioterapia, doenças da coróide/quimioterapia; Sistemas de liberação de medicamentos, Vitrectomia; Agentes corantes

\section{INTRODUÇÃO}

A farmacologia ocular e sua aplicação no tratamento de doenças que acometem o vítreo, retina e coróide progrediram muito. O desenvolvimento das ciências básicas como a biologia molecular e bioquímica esclareceu detalhes do mecanismo de ligação das drogas aos receptores de membrana e ativação da cascata de sinalização intracelular até o efeito biológico resultante. Isso permitiu o aprimoramento de moléculas conhecidas e o desenvolvimento de numerosos princípios ativos com ação específica na patogênese de diversas doenças ${ }^{(1-2)}$.

Devido às características fisiológicas do globo ocular, diferentes vias de administração de medicamentos podem ser utilizadas. Embora princípios clássicos de farmacocinética como absorção, distribuição, metabolismo e eliminação determinem a disponibilização dos medicamentos no olho, as barreiras oculares (córnea e barreira hematorretiniana) e vias alternativas de administração de medicamentos introduzem outras variáveis ao se estudar a farmacocinética ocular. Além disso, medicamentos biológicos recentemente apresentados para os oftalmologistas possuem particularidades que precisam ser consideradas. A farmacologia ocular também lida com dificuldades específicas, seja em se obter amostras de tecidos ou fluidos intraoculares para determinação de concentrações de medicamentos administrados, seja para avaliar a toxicidade desses medicamentos quando administrados diretamente sobre a retina ou a necessidade de não interferir com as propriedades ópticas do olho(2-4). 
O objetivo desse trabalho é fornecer uma atualização sobre farmacologia ocular, as principais medicações e suas vias de administração para o tratamento de doenças que acometem o segmento posterior do olho.

\section{Via sistêmica de administração de fármacos para a retina $e$ vítreo}

A baixa penetração intraocular da administração sistêmica de medicamentos é explicada pela fisiologia da barreira hematorretiniana, localizada em dois pontos anatômicos distintos: entre as células do epitélio pigmentado da retina (barreira hematorretiniana externa), na zona occludens exercida por fortes aderências intercelulares e entre as células endoteliais, na parede vascular interna dos capilares retinianos (barreira hematorretiniana interna). Estas fortes aderências intercelulares impedem a passagem de moléculas para a cavidade vítrea, incluindo água, íons, antibióticos e outros fármacos. Em casos de inflamação intraocular importante, estas barreiras não exercem suas funções adequadamente ${ }^{(5)}$.

A concentração intraocular de fármacos está diretamente relacionada à concentração sanguínea. Além disso, a tentativa de se elevar os níveis de medicamentos resulta em maior risco de efeitos colaterais sistêmicos. Imunossupressores utilizados em casos de uveítes graves, como corticóides, ciclosporina, metrotrexate e anticorpos monoclonais específicos para a inibição do fator de necrose tumoral como o infliximab, (Remicade ${ }^{\circledR}$, Schering-Plough) podem desencadear sérios efeitos colaterais que limitam sua aplicação. Particularmente, no caso de fatores inibidores de crescimento de células endoteliais vasculares, o desencadeamento de eventos tromboembólicos cardíacos ou no sistema nervoso central pode causar infarto agudo do miocárdio ou acidente vascular cerebral respectivamente, dentre outras complicações ${ }^{(6)}$.

\section{Via tópica de administração de fármacos para a retina $e$ vitreo}

Cerca de $90 \%$ dos medicamentos disponíveis para os oftalmologistas são formulados na forma de colírios sendo administrados pela via tópica. A medicação aplicada pela via tópica pode ter dois objetivos: o tratamento de doenças da superfície ocular, como conjuntivites, blefarite e olho seco ou intraoculares, como glaucoma e uveítes. Para o tratamento das primeiras, a aplicação tópica de medicamento diretamente na córnea e conjuntiva é ideal, devido à sua simplicidade, eficácia e segurança. Já para o tratamento de doenças intraoculares, as diversas barreiras que o fármaco deve ultrapassar dificultam a obtenção de doses terapêuticas no tecido alvo, especialmente na retina e no vítreo. Estima-se que a absorção intraocular na câmara anterior seja entre 1 e 5\% da dose administrada ${ }^{(4,6)}$.

A drenagem do filme lacrimal, o reflexo de lacrimejamento e piscar no ato de instilar o colírio e o limitado volume da solução capaz de se manter no fundo do saco conjuntival eliminam rapidamente a maior parte da droga administrada.
Associam-se a estes fatores a ligação da droga a proteínas do filme lacrimal, seu metabolismo por proteínas dos tecidos e sua difusão através da córnea e conjuntiva para a circulação sistêmica $^{(2)}$.

Propriedades físicas e químicas da substância também são fatores envolvidos na capacidade de difusão da droga através da córnea, como lipofilia, solubilidade, concentração, massa molecular, forma da molécula, carga da molécula e grau de ionização. Dentre estas, destacam-se as interações hidrofóbicas e hidrofílicas entre o fármaco e a córnea. A córnea pode ser imaginada com uma estrutura trilaminar: "lipídeo-águalipídeo", respectivamente correspondentes ao epitélio, estroma e endotélio corneal. O epitélio e endotélio representam barreiras para substâncias hidrofílicas e o estroma funciona como barreira para componentes hidrofóbicos. Portanto, uma droga precisa apresentar características hidrofílicas e hidrofóbicas simultaneamente para obter boa penetração através da córnea ${ }^{(2)}$.

Algumas fórmulas administradas pela via tópica prolongam o tempo que o medicamento permanece na superfície ocular, e assim otimizam sua absorção intraocular: são os géis, pomadas e lentes de contato gelatinosas. Por muito tempo essas fórmulas foram utilizadas durante o período noturno, associadas aos colírios no período diurno, entretanto sem alcançar níveis terapêuticos suficientes para o tratamento de patologias vitreorretinianas ${ }^{(2)}$.

Géis oftálmicos são compostos hidrofílicos disponíveis em nosso meio como lubrificantes, pilocarpina e xilocaína. Os géis prolongam seu contato com a córnea por propriedades mucoadesivas decorrentes de sua elevada viscosidade e liberam o medicamento por difusão após erosão do polímero que se hidrolisa ${ }^{(4)}$. Os polímeros incluem ésteres de celulose, álcool polivinílico, carbopol, poliacrilamida, ácido hialurônico e ácido plurônico ${ }^{(2)}$. Pomadas são lipofílicas e geralmente contêm óleo mineral e base de vaselina e lanolina; atuam através dos mesmos princípios dos géis e são utilizadas em fórmulas geralmente contendo antibióticos, agentes cicloplégicos, corticóides e mióticos ${ }^{(2,7)}$.

Mesmo após ter sido ultrapassada a barreira corneal, a penetração do princípio ativo na retina e na coróide é pequena devido à grande extensão física que deve ser percorrida para que estes tecidos sejam atingidos. A concentração de antibióticos tópicos, como ofloxacina a $0,3 \%$ e ciprofloxacina a $0,3 \%$, é cinco vezes menor no vítreo do que na câmara anterior $^{(8)}$.

Todas as medicações administradas pela via tópica são potencialmente absorvidas pela circulação sistêmica primariamente através das mucosas nasal e ocular; portanto, efeitos colaterais sistêmicos podem acontecer.

O colírio maleato de timolol é amplamente utilizado para tratamento de glaucoma em nosso meio e pode levar a broncoespasmo e óbito. Além da baixa penetração ocular desta via de administração, o desconforto ao instilar o colírio e reações locais de hipersensibilidade ou toxicidade direta na córnea, conjuntiva, pele da região periocular e mucosa nasal 
podem ocorrer, como por exemplo, pelo cloreto de benzalcônio, causando ceratopatia punteada ou ulcerativa. Outro problema frequente desta via de administração é o uso incorreto do colírio pelo paciente e sua fidelidade ao tratamento, especialmente em doenças crônicas como o glaucoma ${ }^{(2)}$.

Entretanto, há estudos sobre o uso de anti-inflamatórios não hormonais administrados através da via tópica para tratamento de edema macular cistóide. Um exemplo é o nepafenac (Nevanac, Alcon), indicado em pacientes que evoluíram com elevação da pressão intraocular ao utilizarem colírios de corticóides. Tal medicamento é composto por uma pró-droga com boa penetração através da córnea e esclera, que quando degradada por enzimas hidrolíticas intraoculares, transforma-se em um metabólito mais ativo chamado anfenac, que inibe cicloxigenases. Essas enzimas são encontradas em tecidos oculares como córnea, íris, corpo ciliar, mas em maiores concentrações no complexo retina-coróide. Com isso, acredita-se que haja uma bioativação da droga no tecido-alvo, a mácula ${ }^{(9)}$.

\section{Via periocular de administração de fármacos para a retina $e$ vítreo}

Uma das particularidades da prática oftalmológica são vias alternativas de administração de medicamentos, entre elas a via de administração periocular, seja subconjuntival, subtenoniana ou retrobulbar. Essas vias não enfrentam as barreiras exercidas pelo epitélio da córnea e da conjuntiva e, portanto, apresentam algumas vantagens sobre as vias sistêmica e tópica no que diz respeito à obtenção de concentrações adequadas no meio intraocular ${ }^{(10)}$. Comparada às injeções intravítreas, a administração periocular anterior é mais segura por ser menos invasiva. Ela pode apresentar absorção imediata ou sustentada ao longo do tempo, conforme a fórmula do medicamento utilizado ${ }^{(11-12)}$. Diversos grupos utilizam a via de administração transescleral de medicamentos como primeira escolha para que se obtenham concentrações terapêuticas na cavidade vítrea e na retina e coróide ${ }^{(13-14)}$.

A esclera é pesquisada como potencial via de administração de medicamentos por sua superfície de área extensa e acessível, com boa tolerância a implantes em sua superfície. Seu alto grau de hidratação proporciona transporte de substâncias hidrossolúveis e sua hipocelularidade resulta na presença de poucas enzimas proteolíticas, que degradariam a molécula do fármaco ${ }^{(13-14)}$.

A permeabilidade escleral é comparável à do estroma corneano. O tamanho molecular e a hidrossolubilidade são dois fatores importantes envolvidos no mecanismo de transporte transescleral. Constatou-se que a permeabilidade sofre um declínio exponencial com o aumento da massa molecular e do raio do soluto ${ }^{(15)}$. Autores acreditam que o tamanho da molécula seja o fator determinante mais importante da permeabilidade escleral, pois seu mecanismo acontece por difusão passiva através de múltiplos canais com diferentes tamanhos limitantes, através do tecido hipocelular ${ }^{(8)}$. Entretanto, mesmo grandes moléculas hidrofílicas, como proteínas, têm boa penetração escleral ${ }^{(16)}$.

A barreira hematorretiniana externa exercida pelas aderências intercelulares do epitélio pigmentado da retina diminui a permeabilidade intraocular de muitos compostos que atravessam a esclera, sendo então eliminados rapidamente pela coróide ${ }^{(5,10,14-15)}$. Portanto o transporte transescleral parece promissor para fármacos hidrofílicos que tenham como tecido alvo a coróide, pois atravessariam a esclera e alcançariam a coróide ${ }^{(15-16)}$

Implantes episclerais de betametasona não absorvíveis podem atingir níveis terapêuticos por quatro semanas em olhos de coelhos, embora o procedimento de implantação cirúrgica na episclera do polo posterior seja invasivo. Essas metodologias não potencializam o transporte através das barreiras oculares, mas apenas liberam o medicamento continuamente, com a vantagem de prolongar o tempo de ação do fármaco durante o tratamento ${ }^{(17)}$.

Outro fator envolvido nas vias de administração apresentadas até agora é a pressão intraocular (PIO). Autores demonstraram que o aumento da $\mathrm{PIO}$ está inversamente relacionado à permeabilidade escleral, e que um aumento de $15 \mathrm{mmHg}$ diminuiria pela metade a permeabilidade escleral a moléculas pequenas. Autores sugerem que a PIO elevada diminui a permeabilidade escleral não por induzir fluxo hidrostático contrário, mas sim por compressão mecânica das fibras esclerais e estreitamento das vias de difusão ${ }^{(18)}$.

Embora as vias de administração sistêmica, tópica e periocular não satisfaçam plenamente o oftalmologista em relação à obtenção de níveis terapêuticos para doenças da retina e coróide, elas continuam sendo utilizadas ${ }^{(8)}$.

\section{Via intravitrea de adminstração de fármacos}

Devido às características anatômicas e fisiológicas do olho humano, a administração de medicamentos diretamente na cavidade vítrea por meio de injeções é especialmente interessante no tratamento de doenças vitreorretinianas. A injeção intravítrea é capaz de disponibilizar altas doses de solução aquosa ou suspensão do medicamento diretamente na cavidade vítrea. A partir de 1974 autores publicam toxicidade e meia-vida de diversos antibióticos administrados através de injeção intravítrea ${ }^{(3,19)}$.

No início, as injeções intravítreas eram restritas aos casos graves de endoftalmite e devido à proximidade entre a dose terapêutica e tóxica, a quantidade de medicamento injetada sempre foi cuidadosamente calculada ${ }^{(19)}$. Além da endoftalmite bacteriana, a retinite viral por citomegalovírus também requer tratamento com injeção intravítrea, neste caso com ganciclovir. Realizada sob condições de assepsia, é considerada a mais eficiente via de administração de medicamentos para o tratamento de doenças inflamatórias, infecciosas e proliferativas do segmento posterior ${ }^{(1,3,20-21)}$.

Medicamentos hidrofílicos introduzidos no vítreo são preferencialmente eliminados através da hialóide anterior para a câmara anterior e para fora do olho pela drenagem pelo 
trabeculado. Medicamentos lipofílicos têm maior facilidade de penetrar na retina e serem eliminados pela coróide e esclera, embora a via anterior também tenha um papel importante. Finalmente, a absorção pela íris e cristalino é desprezível ${ }^{(22)}$.

Grande parte dos pacientes requer tratamento por longos períodos. Os medicamentos administrados na cavidade vítrea não têm sua taxa de liberação controlável e sua duração de ação é determinada pela meia-vida. Frequentemente, múltiplas aplicações são necessárias.

A tentativa de prolongar os níveis intraoculares, injetando-se maiores doses destes compostos, está diretamente relacionada ao risco de toxicidade para a retina. Podemos tomar como exemplo a triancinolona acetonida (TA), amplamente utilizada por diminuir a permeabilidade vascular e atividade inflamatória, ação antagônica ao mecanismo fisiopatológico de importantes doenças. Administrada diretamente na cavidade vítrea em uma dose segura de 4 miligramas, é utilizada para o tratamento de edema macular diabético, edema macular cistóide após cirurgia de catarata e outras patologias. Sistemas de liberação controlada de TA na cavidade vítrea utilizam taxas de liberação muito inferiores, entre 5-10 microgramas por $\mathrm{dia}^{(23)}$.

\section{Anticorpos monoclonais}

A administração de anticorpos monoclonais diretamente na cavidade vítrea revolucionou o tratamento de doenças vitreorretinianas. Inibidores do fator de crescimento do endotélio vascular (VEGF), desenvolvidos para oncologia, passaram a ter novas indicações - chamadas "off label", termo que significa uso para tratamento de doenças que não foram estudadas durante o desenvolvimento do medicamento e que, portanto, não constam na bula do produto ${ }^{(1,24-25)}$.

Estudo sobre farmacocinética do bevacizumabe (Avastin, Genentech), um inibidor dos receptores subtipo A do VEGF, indica que cerca de 2 horas após a aplicação intravítrea em olhos de coelhos, a molécula atinge o espaço sub-retiniano dos animais, o que explica o efeito clínico rápido dessa medicação quando utilizada em olhos humanos ${ }^{(26)}$. O bevacizumabe reduz a neovascularização e diminui a permeabilidade vascular em pacientes com degeneração macular relacionada à idade (DMRI) e retinopatia diabética. Também, mostrou-se eficiente em oclusões vasculares da retina, neovascularização corneana, glaucoma neovascular e retinopatia da prematuridade ${ }^{(1,24-25)}$.

Recentemente, foi disponibilizado aos oftalmologistas um fragmento de anticorpo humano recombinado capaz de inibir o VEGF, o ranibizumabe (Lucentis, Genentech). Em ensaios clínicos prospectivos, essa medicação estabilizou a visão em aproximadamente $95 \%$ dos pacientes com membrana neovascular sub-retiniana secundária a DMRI durante o primeiro ano de tratamento e em aproximadamente $90 \%$ ao final do segundo ano ${ }^{(27-28)}$. Entretanto, a curta meia-vida dos anticorpos monoclonais na cavidade vítrea é uma das limitações do tratamento. Doenças coriorretinianas crônicas necessitam de múltiplas aplicações, com consequente aumento do risco de complicações graves relacionadas ao procedimento, como descolamento de retina, hemorragia vítrea ou endoftalmite. Além disso, devem ser considerados o desconforto do paciente e a possibilidade de diminuição da adesão ao tratamento $^{(29)}$.

\section{Sistemas de liberação controlada}

Uma alternativa para que se mantenham níveis terapêuticos do fármaco no meio intraocular são os sistemas intravítreos de liberação controlada de medicamentos para o segmento posterior do olho. Estudados por diversos grupos, esses sistemas utilizam diferentes tecnologias, como lipossomos, micropartículas, sistemas de reservatórios ou matriciais. A duração de qualquer sistema é diretamente proporcional à quantidade de fármaco armazenada nele. Quanto maior a velocidade de difusão, mais rápida a liberação e mais breve a duração do sistema. Para determinada velocidade de liberação, quanto maior for a quantidade de medicamento inicialmente disponível no implante, mais prolongada será a duração da liberação do sistema e por mais tempo será possível manter os níveis intraoculares do medicamento ${ }^{(3,6,30)}$.

\section{Sistemas de liberação controlada - lipossomos}

Sistemas de lipossomos são compostos por vesículas biocompatíveis e biodegradáveis, com estrutura semelhante à de membranas celulares, que formam uma dupla camada de lipídeos separados por uma fase aquosa, com um componente aquoso interno. Podem ser utilizados para armazenar o medicamento dentro dessas vesículas por diferentes meios, reduzindo efeitos colaterais e tornando os fármacos já existentes mais seguros. Proporcionam maiores concentrações no tecido alvo, e assim potencializam o efeito terapêutico do fármaco, tornando-o mais eficiente ${ }^{(30)}$.

Fármacos lipofílicos ligam-se à membrana da vesícula, enquanto os fármacos lipofóbicos ou polares permanecem encapsulados na porção aquosa dentro do lipossomo. Séries de estudos demonstram aumento da meia-vida, especificidade e biodisponibilidade através de membranas, bem como diminuição da toxicidade de antibióticos, antifúngicos, antivirais e antimetabólicos encapsulados em lipossomos, além da proteção contra enzimas inativadoras. Dificuldades encontradas nesses métodos incluem a complexidade de seu preparo, o processo de esterilização e o uso de lipídeos. Essas fórmulas se espalham difusamente no vítreo, interferindo nas propriedades ópticas e na acuidade visual do paciente, podendo dificultar o exame da retina por um período de 14 a $21 \operatorname{dias}^{(31)}$.

\section{Sistemas de liberação controlada - micropartículas}

Sistemas de micropartículas são usados para encapsular medicamentos e assim aumentar sua meia-vida e limitar sua toxicidade na retina. Micropartículas são constituídas por polímeros, frequentemente de ácido lático ou ácido glicólico, com tamanho entre 10 e 1000 nanômetros, mais facilmente produzidas do que os lipossomos e permitem maior controle de liberação do medicamento ${ }^{(31-32)}$. 


\section{Sistemas de liberação controlada - implantes}

O implante reservatório de ganciclovir (Vitrasert, Bausch \& Lomb), desenvolvido no início da década de 90, teve atuação importante no tratamento da retinite por citomegalovírus. Funciona como um reservatório, implantado cirurgicamente e suturado na pars plana, do qual o medicamento se difunde através da membrana semipermeável, capaz de sustentar a dose terapêutica por oito meses, sem picos de concentração da droga. Permitiu pela primeira vez que os médicos os administrassem de maneira controlada na cavidade vítrea, evitando toxicidade sistêmica. O principal ponto negativo desse sistema é a necessidade de uma esclerotomia ampla para inserção do dispositivo, de 3 a 5 milímetros, que pode elevar o risco de complicações, como descolamento de retina, hemorragias e infecções. Implante semelhante de dexametasona também foi desenvolvido ${ }^{(33)}$.

Outros implantes intravítreos utilizam o sistema matricial para liberação controlada de medicamentos. Compostos por uma plataforma polimérica biodegradável (acido lático e glicólico) que libera o medicamento de sua estrutura conforme se hidrolisa, foram desenvolvidos com corticóides como fluocinolona e dexametasona. Estudados no tratamento de uveítes posteriores não infecciosas, atingiram resultado clínico por até 3 anos, entretanto com complicações importantes, como glaucoma, catarata e oclusões vasculares da retina. Essas complicações foram interpretadas como efeito colateral das altas doses do medicamento utilizado ${ }^{(23,34-36)}$.

\section{Outras aplicações da farmacologia ocular}

A farmacologia ocular também esta envolvida no desenvolvimento de compostos que auxiliam procedimentos cirúrgicos vitreorretinianos, como substitutos vítreos e corantes. Corantes são componentes químicos que se ligam a substâncias e alteram sua aparência, facilitando assim a diferenciação de outros tecidos e atuando como ferramentas úteis para a identificação de microestruturas durante procedimentos cirúrgicos ${ }^{(37-38)}$. Uma técnica cirúrgica específica utilizada em cirurgias de mácula envolve a retirada da membrana limitante interna, e trabalhos apontam uma progressiva experiência cirúrgica com corantes como a indocianina verde, azul brilhante (ideais para corar a membrana limitante interna), azul de tripan e azul patente (indicado para corar a membrana epirretiniana) e acetonido de triancinolona (que se deposita sobre a hialóide posterior, facilitando assim sua identificação $)^{(39-40)}$. Pesquisas laboratoriais são realizadas para se estabelecer mecanismos de toxicidade dos corantes conhecidos (concentrações, osmolaridade, carga elétrica, fototoxicidade), assim como explorar a capacidade de tingimento dos novos corantes ${ }^{(39-40)}$

\section{Considerações finais}

O desenvolvimento da farmacologia ocular aplicada à terapêutica das doenças que acometem a cavidade vítrea, retina e coróide impulsiona a pesquisa de novas drogas, me- todologias de controle de liberação de medicamentos no local da doença e outras aplicações como a cromovitrectomia. O médico oftalmologista necessita de conhecimento clínico e farmacológico para otimizar o efeito terapêutico do número crescente de fármacos com diferentes mecanismos de ação para tratamento das doenças vitreorretinianas. Atualmente, mesmo os casos de conduta cirúrgica envolvem farmacologia ocular.

O desenvolvimento de novos princípios ativos é uma das fronteiras da farmacologia ocular moderna. Nesse contexto, o desenvolvimento de metodologias que viabilizem o acesso de fármacos ao tecido-alvo e mantenham sua concentração de maneira segura em níveis satisfatórios por tempo determinado pode ser tão importante quanto o desenvolvimento de novos princípios ativos terapêuticos. Novos estudos são necessários para otimizar o uso dos fármacos no segmento posterior do olho.

\section{ABSTRACT}

Retinal diseases are frequently causes of impaired visual acuity and blindness. Recent progress in ocular pharmacology leads to the development of new promising drugs and better functional outcomes. Drug delivery and local management of diseases affecting the choroid and retina should enable better a natomical and functional outcomes. An overview of ocular pharmacology, emerging drug technologies and drug delivery is provided. Some relevant clinical features are discussed.

Keywords: Eye diseases/drug therapy; Retinal diseases/drug therapy; Choroidal diseases/drug therapy; Drug delivery systems; Vitrectomy; Coloring agents

\section{REFERÊNCIAS}

1. Rosenfeld PJ, Moshfeghi AA, Puliafito CA. Optical coherence tomography findings after an intravitreal injection of bevacizumab (avastin) for neovascular age-related macular degeneration. Ophthalmic Surg Lasers Imaging. 2005 36(4):331-5. Comment in: Ophthalmic Surg Lasers Imaging. 2005;36(4):270-1.

2. Lima Filho AAS, Dantas AM, Sallum JMF, Ferreira Filho N, Marback RL. Fisiologia da retina e das vias ópticas. In: Conselho Brasileiro de Oftalmologia. Bases da oftalmologia. São Paulo: Cultura Médica; 2008. p.627-794. (Série Brasileira de Oftalmologia).

3. Peyman GA, Ganiban GJ. Delivery systems for intraocular routes. Adv Drug Deliv Rev. 1995;16(1):107-23

4. Bourlais CL, Acar L, Zia H, Sado PA, Needham T, Leverge R. Ophthalmic drug delivery systems-recent advances. Prog Retin Eye Res. 1998;17(1):33-58. Review.

5. Forrester D, McMenamin L. Biochemistry. In: Forrester JV, Dick AD, McMenamin PG, Lee WR. The eye: basic sciences in practice. $2^{\text {nd }}$ ed. New York: Saunders; 2002. p.143-52.

6. Geroski DH, Edelhauser HF. Drug delivery for posterior segment eye disease. Invest Ophthalmol Vis Sci. 2000;41(5):961-4

7. Keller N, Tsao SW, Chandrasekaran K, Hatfield JM. Ocular kinetics of extended duration fluorometholone $(0.1 \%)$ formulations vs ointment and aqueous suspension. Invest Ophthalmol Vis Sci. 1993;34(Suppl):1490-1.

8. Yalvac IS, Basci NE, Bozkurt A, Duman S. Penetration of topically applied ciprofloxacin and ofloxacin into the aqueous humor and vitreous. J Cataract Refract Surg. 2003;29(3):487-91. 
9. Warren KA, Fox JE. Topical nepafenac as an alternative treatment for cystoid macular edema in steroid responsive patients. Retina. 2008;28(10):1427-34.

10. Geroski DH, Edelhauser HF. Transscleral drug delivery for posterior segment disease. Adv Drug Deliv Rev. 2001;52(1):37-48. Review.

11. Okabe J, Kimura H, Kunou N, Okabe K, Kato A, Ogura Y. Biodegradable intrascleral implant for sustained intraocular delivery of betamethasone phosphate. Invest Ophthalmol Vis Sci. 2003;44(2):740-4.

12. Kompella UB, Bandi N, Ayalasomayajula SP. Subconjunctival nano- and microparticles sustain retinal delivery of budesonide, a corticosteroid capable of inhibiting VEGF expression. Invest Ophthalmol Vis Sci. 2003;44(3):1192-201.

13. Ambati J, Adamis AP. Transscleral drug delivery to the retina and choroid. Prog Retin Eye Res. 2002;21(2):145-51. Review.

14. Weijtens O, Schoemaker RC, Lentjes EG, Romijn FP, Cohen AF, van Meurs JC. Dexamethasone concentration in the subretinal fluid after a subconjunctival injection, a peribulbar injection, or an oral dose. Ophthalmology. 2000;107(10):1932-8.

15. Ambati J, Canakis CS, Miller JW, Gragoudas ES, Edwards A, Weissgold DJ, et al. Diffusion of high molecular weight compounds through sclera. Invest Ophthalmol Vis Sci. 2000;41(5):1181-5.

16. Ambati J, Gragoudas ES, Miller JW, You TT, Miyamoto K, Delori FC, Adamis AP. Transscleral delivery of bioactive protein to the choroid and retina. Invest Ophthalmol Vis Sci. 2000;41(5):1186-91

17. Kato A, Kimura H, Okabe K, Okabe J, Kunou N, Ogura Y. Feasibility of drug delivery to the posterior pole of the rabbit eye with an episcleral implant. Invest Ophthalmol Vis Sci. 2004;45(1):238-44.

18. Rudnick DE, Noonan JS, Geroski DH, Prausnitz MR, Edelhauser HF. The effect of intraocular pressure on human and rabbit scleral permeability. Invest Ophthalmol Vis Sci. 1999;40(12):3054-8

19. Peyman GA, Herbst R. Bacterial endophthalmitis. Treatment with intraocular injection of gentamicin and dexamethasone. Arch Ophthalmol. 1974;91(5):416-8.

20. Cochereau-Massin I, Lehoang P, Lautier-Frau M, Zazoun L, Marcel P, Robinet $\mathrm{M}$, et al. Efficacy and tolerance of intravitreal ganciclovir in cytomegalovirus retinitis in acquired immune deficiency syndrome. Ophthalmology. 1991;98(9): 1348-53; discussion 1353-5.

21. Aiello LP, Brucker AJ, Chang S, Cunningham ET Jr, D'Amico DJ, Flynn HW Jr, et al. Evolving guidelines for intravitreous injections. Retina. 2004; 24(5 Suppl):S3-19. Review.

22. Tano Y, Sugita G, Abrams G, Machemer R. Inhibition of intraocular proliferations with intravitreal corticosteroids. Am J Ophthalmol. 1980;89(1):131-6.

23. Mello-Filho PA, Guven D, Beeley NR, de Juan E Jr, Erickson SR. Helical intravitreal triamcinolone acetonide implant: a 6-month surgical feasibility study in rabbits. Ophthalmic Surg Lasers Imaging. 2009;40(2):160-8.

24. Rodrigues EB, Farah ME, Maia M, Penha FM, Regatieri C, Melo GB, et al. Therapeutic monoclonal antibodies in ophthalmology. Prog Retin Eye Res. 2009; 28(2):117-44. Review.

25. Spaide RF, Fisher YL. Intravitreal bevacizumab (Avastin) treatment of proliferative diabetic retinopathy complicated by vitreous hemorrhage. Retina. 2006; 26(3):275-8.
26. Dib E, Maia M, Longo-Maugeri IM, Martins MC, Mussalem JS, Squaiella $\mathrm{CC}$, et al. Subretinal bevacizumab detection after intravitreous injection in rabbits. Invest Ophthalmol Vis Sci. 2008;49(3):1097-100.

27. Rosenfeld PJ, Brown DM, Heier JS, Boyer DS, Kaiser PK, Chung CY, Kim RY; MARINA Study Group. Ranibizumab for neovascular age-related macular degeneration. N Engl J Med. 2006;355(14):1419-31.

28. Brown DM, Kaiser PK, Michels M, Soubrane G, Heier JS, Kim RY, Sy JP, Schneider S; ANCHOR Study Group. Ranibizumab versus verteporfin for neovascular age-related macular degeneration. N Engl J Med. 2006;355(14): 1432-44. Comment in: N Engl J Med. 2006;355(14):1409-12. N Engl J Med. 2007;356(7):748-9; author reply 749-50. N Engl J Med. 2007;356(7):747-8; author reply 749-50. N Engl J Med. 2006;355(14):1493-5.

29. Jager RD, Aiello LP, Patel SC, Cunningham ET Jr. Risks of intravitreous injection: a comprehensive review. Retina. 2004;24(5):676-98.

30. Akula SK, Ma PE, Peyman GA, Rahimy MH, Hyslop NE Jr, Janney A, Ashton P. Treatment of cytomegalovirus retinitis with intravitreal injection of liposome encapsulated ganciclovir in a patient with AIDS. Br J Ophthalmol. 1994;78(9):677-80.

31. Peyman GA, Charles HC, Liu KR, Khoobehi B, Niesman M. Intravitreal liposome-encapsulated drugs: a preliminary human report. Int Ophthalmol. 1988; 12(3):175-82.

32. Moritera T, Ogura Y, Honda Y, Wada R, Hyon SH, Ikada Y. Microspheres of biodegradable polymers as a drug-delivery system in the vitreous. Invest Ophthalmol Vis Sci. 1991;32(6):1785-90.

33. Musch DC, Martin DF, Gordon JF, Davis MD, Kuppermann BD. Treatment of cytomegalovirus retinitis with a sustained-release ganciclovir implant. The Ganciclovir Implant Study Group. N Engl J Med. 1997;337(2):83-90.

34. Holekamp NM, Thomas MA, Pearson A. The safety profile of long-term, highdose intraocular corticosteroid delivery. Am J Ophthalmol. 2005;139(3):421-8. Comment in: Am J Ophthalmol. 2005;139(3):533-5.

35. Jaffe GJ, Pearson PA, Ashton P. Dexamethasone sustained drug delivery implant for the treatment of severe uveitis. Retina. 2000;20(4):402-3.

36. Jaffe GJ, Ben-Num J, Guo H, Dunn JP, Ashton P. Fluocinolone acetonide sustained drug delivery device to treat severe uveitis. Ophthalmology. 2000 107(11):2024-33

37. Penha FM, Maia M, Farah ME, Dib E, Príncipe AH, Devin F, et al. Morphologic and clinical effects of subretinal injection of indocyanine green and infracyanine green in rabbits. J Ocul Pharmacol Ther. 2008;24(1):52-61.

38. Maia M, Haller JA, Pieramici DJ, Margalit E, de Juan E Jr, Farah ME, et al Retinal pigment epithelial abnormalities after internal limiting membrane peeling guided by indocyanine green staining. Retina. 2004;24(1):157-60.

39. Rodrigues EB, Penha FM, Farah ME, de Paula Fiod Costa E, Maia M, Dib E, et al. Preclinical investigation of the retinal biocompatibility of six novel vital dyes for chromevitrectomy. Retina. 2009;29(4):497-510.

40. Rodrigues EB, Penha FM, Furlani B, Meyer CH, Maia M, Farah ME. Historical aspects and evolution of the application of vital dyes in vitreoretinal surgery and chromovitrectomy. Dev Ophthalmol. 2008;42:29-34. 